\title{
Recurrent Malignant Nasopharyngeal Neoplasm
}

National Cancer Institute

\section{Source}

National Cancer Institute. Recurrent Malignant Nasopharyngeal Neoplasm. NCI

Thesaurus. Code C9268.

The reemergence of a nasopharyng eal malignant neoplasm after a period of remission. 